conditions good, flexible land use and the conservation of soil and water are vital, as has long been realised by the Water Resources Council, but greater re-use of waste water and more provision for wildlife is required.

In recent years it has been appreciated that Australia has unique opportunities for wildlife conservation, for national parks and nature reserves that need to be managed to maintain their characteristic value. Such management would not preclude some commercialisation of wildlife, provided this was on a sound ecological basis of humane and hygienic cropping. At a time when mineral exports are increasing and rural exports decreasing in Australia, this book advocates a policy of concentrating on rural production in developed areas and keeping undeveloped land in a nearnatural condition of extensive land-use, leaving some freedom of choice to future generations. Outside the Federal Territories and offshore waters, the States have constitutional powers over most resources in Australia-soil, water, forests, flora, fauna, freshwater fisheries and minerals-but conservation is a personal, a national and an international concern, and the greatest co-operation between individual, State and Commonwealth is necessary if this unique environment is to be maintained.

HARRY V. THOMPSON

\title{
The Life of the Far North, by William A. Fuller and John C. Holmes. McGraw-Hill, £2.50. \\ Polar Worlds, by Richard Perry. David \& Charles, £3.95.
}

The first of these books about the life of polar regions is restricted to the north; the other deals with both ends of the earth's axis. The authors of the first are professional ecologists who have travelled extensively in the far north, and engaged in research at a number of biological stations in both arctic and sub-arctic regions. In lively, non-technical language they guide the reader through the spruce forests of the northern taiga and the wide treeless spaces of the tundra, and give a tremendous amount of interesting information.

Mainly designed for North American readership, the book is divided into three sections; the Northern World; Land of Ice and Snow; and Land of the Long Day. An appendix includes brief descriptions of the national parks, notes on the particular physical and biological features of US and Canadian national parks, an account of permafrost and man's effects upon it, short descriptions of four threatened animal species, and a glossary.

The manuscript was reviewed by a top readability consultant to make certain that it would be easily understood by younger readers. Understandable it certainly is; but most people, especially those who will never have the opportunity to visit arctic regions, will be increasingly irritated to be told 'you will find that ...'; 'the landscape you will see as you fly ...'; 'you might imagine that you were in an insect paradise'. I found myself waiting for the next 'you', and subconsciously counting them. In all other respects it is a splendid book, with more than 100 colour photographs.

By contrast, there are no colour photographs in Richard Perry's Polar Worlds and only four indifferently reproduced black and white ones. Even one of these is misleadingly captioned, for it actually shows the fan-shaped snout of Commonwealth Glacier, and not McMurdo Sound itself. There are 20 drawings of mammals and birds, and four maps. It is curious that, according to the list of illustrations, the detail maps of the north and south polar regions are two small ones showing the $50^{\circ} \mathrm{F}$ isotherm and the limits of the Antarctic Convergence respectively, whereas in fact the larger maps of each region carry far more detail.

The first part of the book deals with the Antarctic and its life, the second 
